\title{
Investigating the factors affecting the survival rate in patients with COVID-19: A retrospective cohort study
}

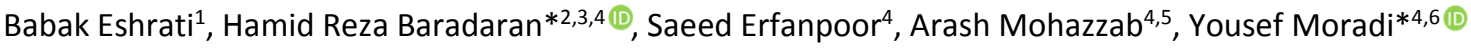 \\ Received: 13 May 2020 \\ Published: 30 Jul 2020
}

\section{Abstract}

Background: As hospitalized patients with COVID-19, especially those who are admitted to ICU or die afterwards, generally have comorbidities, the aim of this study was to determine the factors affecting the survival rate of COVID-19 patients in Iran using a retrospective cohort.

Methods: This retrospective cohort study was conducted on patients with COVID-19 who referred to medical centers under the supervision of Iran University of Medical Sciences, Tehran, Iran, from February 22 to March 25, 2020. The final date of follow-up was April 19, 2020. All consecutive inpatients with laboratory-confirmed COVID-19 were included in this study. Clinical laboratory, radiological, treatment, and demographic data were collected and analyzed. The associations among gender, immune disease, diabetes, liver disease, cardiovascular disease, kidney disease, chronic pulmonary disease, cancer, chronic nervous disease, type of treatment, and risk of death were analyzed. The Kaplan-Meier and Log-rank tests were used to estimate survival rate and compare survival rates, respectively.

Results: The total number of deaths or desired event in the study was $329(10.3 \%)$.The risk of death in the age groups of 50-60 years, $60-70$ years, and $>70$ years compared to the $30-40$ age group was 2.17 (95\% CI: $1.03,4.55$; p: 0.040$)$; 3.72 (95 \% CI: $1.80,7.68$; p: $0.001)$ and 5.09 (95\% CI: 2.49, 10.40; p: 0.001), respectively. The results showed men had $11.5 \%$ more risk of deaths than women (HR: $1.11 ; 95 \%$ CI: $0.89,1.39$; p: 0.341$)$. Kidney disease increased the risk of death by $52.3 \%$ in these patients, which was not statistically significant (HR: 1.78; $95 \%$ CI: 1.04, 3.04; p: 0.035). Also, chronic pulmonary diseases and diabetes increased the risk of death in COVID-19 patients by $89.5 \%$ and $41.3 \%$ compared to COVID-19 patients without chronic pulmonary diseases and diabetes [(HR: 1.89; $95 \%$ CI: 1.17, 3.04; p: 0.008), (HR: 1.41; $95 \%$ CI: 1.01, 1.96; p: 0.038)].

Conclusion: Based on the results of this study, more attention and care should be paid to COVID-19 patients with underlying diseases, such as chronic obstructive pulmonary disease, diabetes, and kidney disease to reduce the number of deaths.

Keywords: Survival Rate, Death, Risk Factors, COVID-19, Iran

Conflicts of Interest: None declared

Funding: This study was financially supported by the Deputy of Research and Technology of Iran University of Medical Sciences, Tehran, Iran (Grant no. 17571).

*This work has been published under CC BY-NC-SA 1.0 license.

Copyright $\subseteq$ Iran University of Medical Sciences

Cite this article as: Eshrati B, Baradaran HR, Erfanpoor S, Mohazzab A, Moradi Y. Investigating the factors affecting the survival rate in patients with COVID-19: A retrospective cohort study. Med J Islam Repub Iran. 2020 (30 Jul);34:88. https://doi.org/10.47176/mjiri.34.88

Corresponding authors: Dr Hamid Reza Baradaran, baradaran.hr@iums.ac.ir YousefMoradi, moradi.y@iums.ac.ir

1. Preventive Medicine and Public Health Research Center, Iran University of Medical Sciences, Tehran, Iran

2. Endocrine Research Center, Institute of Endocrinology and Metabolism, Iran University of Medical Sciences, Tehran, Iran

3. Ageing Clinical \& Experimental Research Team, Institute of Applied Health Sciences, University of Aberdeen, UK

4. Department of Epidemiology, School of Public Health, Iran University of Medical Sciences, Tehran, Iran

5. Reproductive Biotechnology Research Center, Avicenna Research Institute, ACECR, Tehran, Iran

6. Social Determinants of Health Research Center, Research Institute for Health Development, Kurdistan University of Medical Sciences, Sanandaj, Iran $\uparrow$ What is "already known" in this topic:

As hospitalized patients, especially the cases leading to hospitalization in the ICU or death, generally have comorbidities such as diabetes, hypertension, chronic cardiovascular disease, etc. and epidemiological features of the above will be an important finding, determining mortality rates and the factors affecting it can be helpful in proper understanding of each patient's prognosis as well as comprehensive management of COVID-19 control and treatment.

\section{$\rightarrow$ What this article adds:}

Kidney disease increased the risk of death by $52.3 \%$ in these patients, which was not statistically significant. Also, chronic pulmonary diseases and diabetes increased the risk of death in COVID-19 patients by $89.5 \%$ and $41.3 \%$ compared to COVID-19 patients without chronic pulmonary diseases and diabetes. 


\section{Introduction}

The novel Coronavirus (COVID-19) was first reported in December 2019 as an unknown pneumonia in Wuhan, China (1-3). The disease, which occurs following infection with the nCov2019 virus, leads to respiratory distress and acute respiratory distress syndrome. The outbreak was reported by Lee et al with 425 patients in Wuhan and the clinical and epidemiological features of the disease (4). The disease usually causes viral pneumonia similar to influenza often about a week after the onset of the first symptoms and causes shortness of breath, decreased oxygen saturation of the blood, and death usually in the older people or those with underlying disorders (4). Renal disorders and septic shock have also been identified as other causes of death from COVID-19 $(4,5)$. Due to the novelty of the disease and the occurrence of most cases in China, the number of COVID-19 related deaths or disabilities is still unknown. The rate of need for intensive care in hospitalized patients in China was reported to be between $23 \%$ and $32 \%$, and the mortality rate was reported to be from $4.3 \%$ to $15 \%$ in the first articles published by Chinese centers $(4,6-8)$. With the spread of the disease to 114 countries, COVID-19 was announced to be a pandemic on March 11, 2020 (3). Changes in the spread of the disease in other countries of the world as well as an increase in the number of diagnosed cases with less severe symptoms led to changes in mortality rates and in the variables affecting death (9). This requires more effort in designing targeted cohort studies to more accurately record these variables and more consistently identify lowsymptom patients $(10,11)$. According to COVID-19 morbidity statistics, Iran is ranked 11th after the United States, Brazil, Russia, Spain, United Kingdom, Italy, France, Germany, Turkey, and India (1). Due to the fact that hospitalized patients, especially the cases leading to hospitalization in the ICU or death, generally have such comorbidities as diabetes, hypertension, chronic cardiovascular disease, etc., and epidemiological features of the above will be an important finding, determining mortality rate and the factors affecting it can be helpful in proper understanding of each patient's prognosis as well as comprehensive management of COVID-19 control and treatment. The aim of this study was to determine the factors affecting the survival rate and risk of death in Iranian patients with COVID-19 using a retrospective cohort.

\section{Methods}

This was a retrospective cohort study that used the recorded data of the Syndromic Care System (Severe Respiratory Infection Syndrome) in Iran University of Medical Sciences, Tehran, Iran. This project was studied and confirmed by Deputy of Research and Technology of Iran University of Medical Sciences, Tehran, Iran (IR.IUMS.REC. 1399.049). All information related to the patients was considered confidential.

In this study, the data of about 11000 people who were suspected of having COVID-19 and who had referred to medical centers under the supervision of Iran University of Medical Sciences, Tehran, Iran, from February 22 to March 25,2020 were examined. The test result of 3188 people was positive on which the final analysis was performed. These people had referred with symptoms such as fever and cough and were hospitalized and tested positive for COVID-19 (CT scan of the lungs and PCR).

The event of this study was death time from COVID-19 and the survival time was considered to be the difference between the disease diagnosis and the patient's death. The timing of patients' visits to medical centers was random.

In this study, information, including hospitalization date, hospital discharge date, time required for death in people with COVID-19, age, sex, underlying diseases (eg, hypertension, diabetes, cardiovascular, and other diseases) was reviewed and analyzed. The inclusion criteria were all people with COVID-19 whose data were fully recorded in hospitals and medical centers under the supervision of the Health Department of Iran University of Medical Sciences. The exclusion criteria were incomplete personal data, such as failure to disclose the date of discharge or hospitalization or other information.

\section{Statistical analysis}

Descriptive statistics included frequency and percentage, which were expressed for all factors. The Kaplan Meier method was used to calculate the survival rate and log-rank test was performed to compare survival rates. The risk of death was demonstrated with hazard ratios with $95 \%$ confidence interval. The single and multiple Cox regression analysis was used to investigate the effect of variables on the survival rate of patients with COVID-19. The stepwise regression analysis was applied in the multiple Cox regression and the multicollinearity problem was completely checked for final selection. The proportional hazard assumption $(\mathrm{PH})$ was tested based on the scaled Schoenfeld residuals for all variables in the Cox regression. All analyses were performed using the IBM SPSS version 26. Pvalue less than 0.05 was considered significant.

\section{Results}

The mean age of patients in this study was $55.05 \pm 0.31$ years. In this retrospective cohort study, the data of 3188 people with COVID-19 were analyzed and the results showed $1263(39.6 \%)$ were women and 1925 (60.4\%) were men. Also, 1764 patients $(55.3 \%)$ did not have a cough when visited and hospitalized, while 1424 (44.7\%) had a cough. Also, $1310(41.10 \%)$ of COVID-19 patients in the study had shortness of breath, while only $218(6.8 \%)$ and $285(8.9 \%)$ had general weakness and fatigue, respectively. Confusion symptoms were also present in 124 individuals $(3.9 \%)$ of the study participants. Also, 340 (10.7\%), 64 $(0.2 \%), 147(4.6 \%)$, and $179(5.6 \%)$ had symptoms of sore throat, diarrhea, nausea and vomiting, and headache, respectively (Table 1). Of the total participants in the study, $401(12.6 \%)$ had cardiovascular disease and $290(9.1 \%) \mathrm{di}-$ abetes. Of the total study participants, $447(14.0 \%)$ received supportive therapy, while $128(0.4 \%)$ and $436(13.7 \%)$ received antibiotic and antiviral therapy, respectively (Table $1)$. The total number of deaths or desired event in the study was $329(10.3 \%)$ (Table 1). 


\begin{tabular}{|c|c|c|c|c|}
\hline \multirow[t]{2}{*}{ Variables } & \multirow[t]{2}{*}{ Total (\%) } & \multicolumn{2}{|c|}{ Status } & \multirow[t]{2}{*}{$\bar{p}$} \\
\hline & & Alive (\%) & Death $(\%)$ & \\
\hline Age & & & & $<0.001^{*}$ \\
\hline$<30$ & $203(6.4)$ & $195(96.1 \%)$ & $8(3.9 \%)$ & \\
\hline $30-40$ & $451(14.1)$ & $438(97.1 \%)$ & $13(2.9 \%)$ & \\
\hline $40-50$ & $560(17.6)$ & $533(95.2 \%)$ & $27(4.8 \%)$ & \\
\hline $50-60$ & $652(20.5)$ & $596(91.4 \%)$ & $56(8.6 \%)$ & \\
\hline $60-70$ & $618(19.4)$ & $529(85.6 \%)$ & $89(14.4 \%)$ & \\
\hline$>70$ & $704(22.1)$ & $568(80.7 \%)$ & $136(19.3 \%)$ & \\
\hline \multicolumn{5}{|l|}{ Gender } \\
\hline Male & $1925(60.4 \%)$ & $1716(89.1 \%)$ & $209(10.9 \%)$ & $0.218^{*}$ \\
\hline Female & $1263(39.6 \%)$ & $1143(90.5 \%)$ & $120(9.5 \%)$ & \\
\hline \multicolumn{5}{|l|}{ Chest Pain } \\
\hline Yes & $93(2.9 \%)$ & $84(90.3 \%)$ & $9(9.7 \%)$ & $0.836^{*}$ \\
\hline No & $3095(97.1 \%)$ & $2775(89.7 \%)$ & $320(10.3 \%)$ & \\
\hline Shortness of breath & & & & $<0.001^{*}$ \\
\hline Yes & $1310(41.10 \%)$ & $1126(86.0 \%)$ & $184(14.0 \%)$ & \\
\hline No & $1878(58.90 \%)$ & $1733(92.3 \%)$ & $145(7.7 \%)$ & \\
\hline \multicolumn{5}{|l|}{ General weakness } \\
\hline Yes & $218(6.8 \%)$ & $195(89.4 \%)$ & $23(10.6 \%)$ & $0.908^{*}$ \\
\hline No & $2970(93.2 \%)$ & $2664(89.7 \%)$ & $306(10.3 \%)$ & \\
\hline \multicolumn{5}{|l|}{ Fatigue } \\
\hline Yes & $285(8.9 \%)$ & $261(91.6 \%)$ & $24(8.4 \%)$ & $0.269^{*}$ \\
\hline No & $2903(91.1 \%)$ & $2598(89.5 \%)$ & $305(10.5)$ & \\
\hline \multicolumn{5}{|l|}{ Confusion } \\
\hline Yes & $124(3.9 \%)$ & $107(86.3 \%)$ & $17(13.7 \%)$ & $0.206^{*}$ \\
\hline No & $3064(96.1 \%)$ & $2752(89.8 \%)$ & $312(10.2 \%)$ & \\
\hline \multicolumn{5}{|l|}{ Sore throat } \\
\hline Yes & $340(10.7 \%)$ & $313(92.1 \%)$ & $27(7.9 \%)$ & $0.127^{*}$ \\
\hline No & $2848(89.3 \%)$ & $2546(89.4 \%)$ & $302(10.6 \%)$ & \\
\hline \multicolumn{5}{|l|}{ Diarrhea } \\
\hline Yes & $64(2 \%)$ & $55(85.9 \%)$ & $9(14.1 \%)$ & $0.320^{*}$ \\
\hline No & $3124(98 \%)$ & $2804(89.8 \%)$ & $320(10.2)$ & \\
\hline \multicolumn{5}{|l|}{ Nausea and Vomiting } \\
\hline Yes & $147(4.6 \%)$ & $133(90.5 \%)$ & $14(9.5 \%)$ & $0.745^{*}$ \\
\hline No & $3041(95.4 \%)$ & $2726(89.6 \%)$ & $315(10.4 \%)$ & \\
\hline Headache & & & & $0.894^{*}$ \\
\hline Yes & $179(5.6 \%)$ & $160(89.4 \%)$ & $19(10.6 \%)$ & \\
\hline No & $3009(94.4 \%)$ & $2699(89.7 \%)$ & $310(10.3 \%)$ & \\
\hline \multicolumn{5}{|l|}{ Cardiovascular } \\
\hline Yes & $401(12.6 \%)$ & $351(87.5 \%)$ & $50(12.5 \%)$ & $0.130^{*}$ \\
\hline No & $2787(87.4 \%)$ & $2508(90.0 \%)$ & $279(10.0)$ & \\
\hline \multicolumn{5}{|l|}{ Liver disease } \\
\hline Yes & $14(0.4 \%)$ & $11(78.6 \%)$ & $3(21.4 \%)$ & $0.169^{\#}$ \\
\hline No & $3174(99.6 \%)$ & $2848(89.7 \%)$ & $326(10.3 \%)$ & \\
\hline \multicolumn{5}{|c|}{ Chronic nervous disease } \\
\hline Yes & $21(0.7 \%)$ & $17(81.0 \%)$ & $4(19.0 \%)$ & $0.265^{\#}$ \\
\hline No & $3167(99.3 \%)$ & $2842(89.7 \%)$ & $325(10.3 \%)$ & \\
\hline Cancer & & & & $0.066^{\#}$ \\
\hline Yes & $41(1.3 \%)$ & $33(80.5 \%)$ & $8(19.5 \%)$ & \\
\hline No & $3147(98.7 \%)$ & $2826(89.8 \%)$ & $321(10.2 \%)$ & \\
\hline \multicolumn{5}{|l|}{ Stomachache } \\
\hline Yes & $23(0.7 \%)$ & $18(78.3 \%)$ & $5(21.7 \%)$ & $0.81^{\#}$ \\
\hline No & $3165(99.3 \%)$ & $2841(89.8 \%)$ & $324(10.2 \%)$ & \\
\hline \multicolumn{5}{|l|}{ Joints pain } \\
\hline Yes & $74(2.3 \%)$ & $64(86.5 \%)$ & $10(13.5 \%)$ & $0.361^{*}$ \\
\hline No & $3114(97.7 \%)$ & $2795(89.8 \%)$ & $319(10.2 \%)$ & \\
\hline Pharynx exudate & & & & \\
\hline Yes & $6(0.2 \%)$ & $5(83.3 \%)$ & 1(16.7\%) & $0.480^{\#}$ \\
\hline No & $3182(99.8 \%)$ & $2854(89.7 \%)$ & $328(10.3 \%)$ & \\
\hline
\end{tabular}

\# Fisher's Exact Test

The rest of the descriptive data of the clinical symptoms of Iranian patients with COVID-19 and their comparison with alive and dead groups are presented in Table 1.

Multivariable and univariate Cox regression were used to analyze the hazard ratio of death in patients with COVID19 (Table 2). Univariate Cox model for age of patients represents statistically significant higher hazard ratio in all age groups $>50$ years in comparison with reference group $(<30$ years), whereas the age groups between 30-40 and 40-50 years did not show any different hazard ratio.

The hazard ratio of death in the age groups of 50-60 years, $60-70$ years, and $>70$ years compared to the younger than 30 age group was 2.17 (95\% CI: $1.03,4.55$; p: 0.040), 3.72 (95 \% CI: 1.80, 7.68; p: 0.001$)$, and 5.09 (95\% CI: 2.49, 10.40; p: 0.001), respectively (Table 2). 


\begin{tabular}{|c|c|c|c|c|}
\hline \multirow[t]{2}{*}{ Variables } & \multirow[t]{2}{*}{ Total $(\%)$} & \multicolumn{2}{|c|}{ Status } & \multirow[t]{2}{*}{$\mathrm{p}$} \\
\hline & & Alive (\%) & Death (\%) & \\
\hline \multicolumn{5}{|l|}{ Eye inflammation } \\
\hline Yes & $7(0.2 \%)$ & $6(85.7 \%)$ & $1(14.3 \%)$ & $0.534^{\#}$ \\
\hline No & $3181(99.8 \%)$ & $2853(89.7 \%)$ & $328(10.3 \%)$ & \\
\hline Dyspnea & & & & $0.75^{\#}$ \\
\hline Yes & $16(0.5 \%)$ & $12(750 \%)$ & $4(25.0 \%)$ & \\
\hline No & $3172(99.5 \%)$ & $2847(89.8 \%)$ & $325(10.2 \%)$ & \\
\hline \multicolumn{5}{|l|}{ Abnormal lung sound } \\
\hline Yes & $32(1 \%)$ & $25(78.1 \%)$ & $7(21.9 \%)$ & $0.041^{\#}$ \\
\hline No & $3156(99 \%)$ & $2834(89.8 \%)$ & $322(10.2 \%)$ & \\
\hline \multicolumn{5}{|c|}{ Abnormal chest $X$ ray } \\
\hline Yes & $316(9.9 \%)$ & $281(88.9 \%)$ & $35(11.1 \%)$ & $0.642^{*}$ \\
\hline No & $2872(90.1 \%)$ & $2578(89.8 \%)$ & $294(10.2 \%)$ & \\
\hline \multicolumn{5}{|l|}{ Coma } \\
\hline Yes & $9(0.3 \%)$ & $4(44.4 \%)$ & $5(55.6 \%)$ & $0.001^{\#}$ \\
\hline No & $3179(99.7 \%)$ & $2855(89.8 \%)$ & $324(10.2 \%)$ & \\
\hline \multicolumn{5}{|l|}{ Cough } \\
\hline Yes & $1424(44.7 \%)$ & $1287(90.4 \%)$ & $137(9.6 \%)$ & $0.244^{*}$ \\
\hline No & $1764(55.3 \%)$ & $1572(89.1 \%)$ & $192(10.9 \%)$ & \\
\hline Immune disease & & & & $0.353^{\#}$ \\
\hline Yes & $4(0.1 \%)$ & $3(75.0)$ & $1(25.0 \%)$ & \\
\hline No & $3184(99.9 \%)$ & $2856(89.7)$ & $328(10.3 \%)$ & \\
\hline \multicolumn{5}{|l|}{ Diabetes } \\
\hline Yes & $290(9.1 \%)$ & $249(85.9 \%)$ & $41(14.1 \%)$ & $0.025^{*}$ \\
\hline No & $2898(90.9 \%)$ & $2610(90.1 \%)$ & $288(9.9 \%)$ & \\
\hline \multicolumn{5}{|l|}{ Kidney disease } \\
\hline Yes & $78(2.4 \%)$ & $64(82.1 \%)$ & $14(17.9 \%)$ & $0.025^{*}$ \\
\hline No & $3110(97.6 \%)$ & $2795(89.9 \%)$ & $315(10.1 \%)$ & \\
\hline \multicolumn{5}{|c|}{ Chronic pulmonary disease } \\
\hline Yes & $90(2.8 \%)$ & $72(80.0 \%)$ & $18(20.0 \%)$ & $0.002^{*}$ \\
\hline No & $3098(97.2 \%)$ & $2787(90.0 \%)$ & $311(10.0 \%)$ & \\
\hline \multicolumn{5}{|l|}{ Type of treatment } \\
\hline Supportive therapy & $447(44.2 \%)$ & $386(86.4 \%)$ & $61(13.6 \%)$ & $0.330^{*}$ \\
\hline Antibiotic & $128(12.7 \%)$ & $116(90.6 \%)$ & $12(9.4 \%)$ & \\
\hline Antiviral treatment & $436(43.1 \%)$ & $373(85.6 \%)$ & $63(14.4 \%)$ & \\
\hline
\end{tabular}

Similar results were obtained in the multivariable analysis of variables using Cox model for age groups comparison:

The hazard ratio of death in the 50-60 age group was 2.19
(95\% CI: 1.04, 4.61; p: 0.038) compared to the reference group, and in the $60-70$ and $>70$ years' age groups it was equal to 3.78 (95\% CI: $1.83,7.82 ; \mathrm{p}: 0.001)$ and $5.14(95 \%$ CI: 2.51, 10.54; p: 0.001), respectively (Fig. 1 and Table 2).

Table 2. Multivariable and univariate Cox regression analysis of factors associated with death in patients with Coronavirus disease 2019 (COVID 19) pneumonia

\begin{tabular}{|c|c|c|c|c|c|c|c|c|c|c|}
\hline \multirow{3}{*}{\multicolumn{2}{|c|}{$\begin{array}{l}\text { Patient characteristics and } \\
\text { findings }\end{array}$}} & \multirow{3}{*}{$\begin{array}{l}\text { Mean of Survival } \\
\text { Time (95\% CI) } \\
\text { (Days) }\end{array}$} & \multicolumn{4}{|c|}{ Univariate Model } & \multicolumn{4}{|c|}{ Multivariable Model } \\
\hline & & & \multirow{2}{*}{$\begin{array}{c}\text { Hazard } \\
\text { Ratio }\end{array}$} & \multicolumn{2}{|c|}{$95 \% \mathrm{CI}$} & \multirow[t]{2}{*}{$P$ value } & \multirow{2}{*}{$\begin{array}{c}\text { Hazard } \\
\text { Ratio }\end{array}$} & \multicolumn{2}{|c|}{$95 \%$ CI } & \multirow[t]{2}{*}{$\mathrm{p}$} \\
\hline & & & & Lower & Upper & & & Lower & Upper & \\
\hline \multirow[t]{6}{*}{ Age } & $<30$ & $\begin{array}{c}27.20 \\
(25.18-29.23)\end{array}$ & 1 & - & - & - & 1 & - & - & - \\
\hline & $30-40$ & $\begin{array}{c}24.88 \\
(24.16-25.60)\end{array}$ & 0.76 & 0.31 & 1.84 & 0.552 & 0.77 & 0.31 & 1.86 & 0.566 \\
\hline & $40-50$ & $\begin{array}{c}24.56 \\
(23.94-25.18)\end{array}$ & 1.23 & 0.55 & 2.70 & 0.607 & 1.24 & 0.56 & 2.75 & 0.582 \\
\hline & $50-60$ & $\begin{array}{c}26.76 \\
(25.62-27.89)\end{array}$ & 2.17 & 1.03 & 4.55 & $0.040 *$ & 2.19 & 1.04 & 4.61 & $0.038^{*}$ \\
\hline & $60-70$ & $\begin{array}{c}25.47 \\
(24.52-26.41)\end{array}$ & 3.72 & 1.80 & 7.68 & $0.001 *$ & 3.78 & 1.83 & 7.82 & $0.001 *$ \\
\hline & $>70$ & $\begin{array}{c}22.61 \\
(21.25-23.97)\end{array}$ & 5.09 & 2.49 & 10.40 & $0.001 *$ & 5.14 & 2.51 & 10.54 & $0.001 *$ \\
\hline \multirow[t]{2}{*}{ Gender } & Female & $\begin{array}{c}26.41 \\
(25.54-27.28)\end{array}$ & 1 & - & - & - & 1 & - & - & - \\
\hline & Male & $\begin{array}{c}25.60 \\
(24.85-26.35)\end{array}$ & 1.11 & 0.89 & 1.39 & 0.341 & 1.15 & 0.91 & 1.44 & 0.223 \\
\hline \multirow[t]{2}{*}{$\begin{array}{l}\text { Immune dis- } \\
\text { ease }\end{array}$} & No & $\begin{array}{c}25.85 \\
(25.25-26.45)\end{array}$ & 1 & - & - & - & 1 & - & - & - \\
\hline & Yes & $\begin{array}{c}16.37 \\
(11.07-21.67)\end{array}$ & 2.10 & 0.29 & 14.98 & 0.458 & 1.16 & - & - & - \\
\hline
\end{tabular}




\begin{tabular}{|c|c|c|c|c|c|c|c|c|c|c|}
\hline \multicolumn{11}{|l|}{ Table 2. Ctd } \\
\hline \multirow{3}{*}{\multicolumn{2}{|c|}{$\begin{array}{l}\text { Patient characteristics and } \\
\text { findings }\end{array}$}} & \multirow{3}{*}{$\begin{array}{c}\text { Mean of Survival } \\
\text { Time }(95 \% \mathrm{CI}) \\
\text { (Days) }\end{array}$} & \multicolumn{4}{|c|}{ Univariate Model } & \multicolumn{4}{|c|}{ Multivariable Model } \\
\hline & & & \multirow{2}{*}{$\begin{array}{c}\text { Hazard } \\
\text { Ratio }\end{array}$} & \multicolumn{2}{|c|}{$95 \% \mathrm{CI}$} & \multirow[t]{2}{*}{$\mathrm{P}$ value } & \multirow{2}{*}{$\begin{array}{c}\text { Hazard } \\
\text { Ratio }\end{array}$} & \multicolumn{2}{|c|}{$95 \% \mathrm{CI}$} & \multirow[t]{2}{*}{$\mathrm{p}$} \\
\hline & & & & Lower & Upper & & & Lower & Upper & \\
\hline \multirow[t]{2}{*}{ Diabetes } & No & $\begin{array}{c}25.93 \\
(25.29-26.57)\end{array}$ & 1 & - & - & - & 1 & - & - & - \\
\hline & Yes & $\begin{array}{c}25.18 \\
(23.71-26.65)\end{array}$ & 1.41 & 1.01 & 1.96 & $0.038^{*}$ & 1.05 & 0.74 & 1.47 & 0.769 \\
\hline \multirow[t]{2}{*}{ Liver Disease } & No & $\begin{array}{c}25.86 \\
(25.26-26.46)\end{array}$ & 1 & - & - & - & 1 & - & - & - \\
\hline & Yes & $\begin{array}{c}16.42 \\
(12.87-19.96)\end{array}$ & 2.14 & 0.68 & 6.69 & 0.188 & 1.33 & 0.41 & 4.25 & 0.625 \\
\hline \multirow[t]{2}{*}{$\begin{array}{l}\text { Cardiovascular } \\
\text { Disease }\end{array}$} & No & $\begin{array}{c}25.82 \\
(25.15-26.48)\end{array}$ & 1 & - & - & - & 1 & - & - & - \\
\hline & Yes & $\begin{array}{c}26.22 \\
(25.23-27.20)\end{array}$ & 1.27 & 0.94 & 1.72 & 0.112 & 0.83 & 0.60 & 1.13 & 0.251 \\
\hline \multirow[t]{2}{*}{$\begin{array}{l}\text { Kidney Dis- } \\
\text { ease }\end{array}$} & No & $\begin{array}{c}25.89 \\
(25.28-26.50)\end{array}$ & 1 & - & - & - & 1 & - & - & - \\
\hline & Yes & $\begin{array}{c}19.83 \\
(17.88-21.78)\end{array}$ & 1.78 & 1.04 & 3.04 & $0.035^{*}$ & 1.52 & 0.88 & 2.64 & 0.130 \\
\hline \multirow{2}{*}{$\begin{array}{l}\text { Chronic Pul- } \\
\text { monary Dis- } \\
\text { ease }\end{array}$} & No & $\begin{array}{c}26.00 \\
(25.41-26.59)\end{array}$ & 1 & - & - & - & 1 & - & - & - \\
\hline & Yes & $\begin{array}{c}21.37 \\
(18.27-24.47)\end{array}$ & 1.89 & 1.17 & 3.04 & $0.008^{*}$ & 1.51 & 0.93 & 2.44 & 0.088 \\
\hline \multirow[t]{2}{*}{ Cancer } & No & $\begin{array}{c}25.89 \\
(25.29-26.50)\end{array}$ & 1 & - & - & - & 1 & - & - & - \\
\hline & Yes & $\begin{array}{c}19.12 \\
(16.74-21.50)\end{array}$ & 1.74 & 0.86 & 3.51 & 0.121 & 1.33 & 0.66 & 2.71 & 0.418 \\
\hline \multirow[t]{2}{*}{$\begin{array}{l}\text { Chronic Nerv- } \\
\text { ous Disease }\end{array}$} & No & $\begin{array}{c}25.86 \\
(25.26-26.46)\end{array}$ & 1 & - & - & - & 1 & - & - & - \\
\hline & Yes & $\begin{array}{c}17.72 \\
(12.91-18.53)\end{array}$ & 2.09 & 0.78 & 5.62 & 0.141 & 1.68 & 0.62 & 4.53 & 0.304 \\
\hline \multirow[t]{3}{*}{$\begin{array}{l}\text { Type of Treat- } \\
\text { ment }\end{array}$} & $\begin{array}{l}\text { Supportive } \\
\text { therapy }\end{array}$ & $\begin{array}{c}25.12 \\
(23.88-26.36)\end{array}$ & 1 & - & - & - & 1 & - & - & - \\
\hline & $\begin{array}{l}\text { Antibiotic } \\
\text { therapy }\end{array}$ & $\begin{array}{c}26.20 \\
(23.53-28.87)\end{array}$ & 0.64 & 0.34 & 1.20 & 0.172 & - & - & - & - \\
\hline & $\begin{array}{l}\text { Antiviral } \\
\text { therapy }\end{array}$ & $\begin{array}{c}20.83 \\
(19.79-21.86) \\
\end{array}$ & 1.10 & 0.77 & 1.57 & 0.583 & - & - & - & - \\
\hline
\end{tabular}

COVID-19 patients than Iranian females both in univariate and multivariate analysis. The results of univariate analysis showed men had $11.5 \%$ more hazard ratio for deaths than women (HR: 1.11; $95 \% \mathrm{CI}: 0.89$, 1.39; p: 0.341 ), but it was not statistically significant. In the multivariable analysis, men were still had more hazard ratio to die than women, but the relationship was not statistically significant (HR: 1.15; 95 \% CI: 0.91, 1.44; p: 0.225) (Fig. 2 and Table 2).

The results of the analysis of the impact of underlying diseases, such as immunodeficiency, diabetes, liver, cardiovascular, renal, cancer, chronic pulmonary and neurological diseases, on mortality of COVID-19 patients showed diabetes, kidney disease, and chronic pulmonary disease have a significant effect on increasing the risk of mortality in the patients, but the effect was significant only in the univariate model.

Univariate models using each mentioned underlying disease demonstrated a statistically significant increased risk for death in patients with diabetes $(\mathrm{HR}=1.41)$, Kidney disease $(\mathrm{HR}=1.78)$, chronic pulmonary diseases $(\mathrm{HR}=1.89)$, and cardiovascular diseases $(H R=1.27)$. Correspondent $P$ values and confidence intervals were demonstrated in Figure 2 and Table 2. Although such increased risks were observed similarly in multivariate analysis with $\mathrm{HR}=1.05$, $1.52,1.51$, and 0.83 for diabetes, kidney diseases, chronic pulmonary diseases, and cardiovascular respectively, these
Cancer in COVID-19 patients also increased the hazard ratio of death, but it was not statistically significant (Fig. 3 and Table 2).

COVID-19 patients are 2.10 times more likely to die if they have immune diseases, but it was not statistically significant in the 2 models (Fig. 3 and Table 2).

The results of the analysis of antibiotic and viral therapies compared to supportive therapy in the univariate model showed viral therapy could reduce the risk of death in COVID-19 patients by $35.3 \%$ as compared to supportive therapy, while antibiotic therapy increased hazard ratio for death in these patients (Fig. 3 and Table 2). Using multivariable analysis to evaluate antiviral drugs prescription was not possible due to large number of missed therapeutic data.

\section{Discussion}

The aim of this study was to determine the factors affecting the mortality of COVID-19 patients in Iran using a retrospective cohort. The results showed the age of 50-60 years, 60-70 years, 70 years and older, diabetes, kidney disease, and chronic pulmonary infections significantly increased the hazard ratio of death in these patients. The hazard ratio of death in the age group of 70 years and older was higher than in other age groups. These results were consistent with those of Onder Graziano et al who showed the number of deaths in the age group of 70-79 years and 80 and older was higher than other age groups (12). The study 


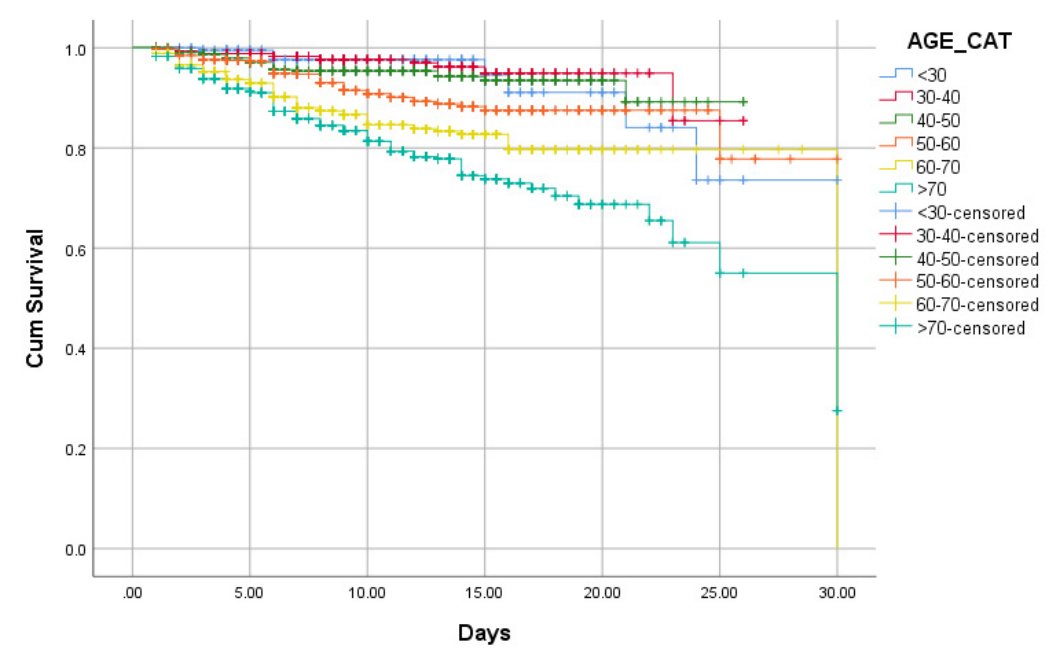

Fig. 1. Survival rate in patients with Coronavirus Disease 2019 (COVID 19) pneumonia based on age (The log Rank Test: 121.24, Df: 5, p: 0.001)

also found the percentage of deaths in age groups over the age of 70 in Italy was higher than in China. However, comparing Iran with other countries, such as China or Italy, for deaths depends on manner and policy of case reporting, ability to diagnose infection and death, diagnostic tests, age, sex, and the socioeconomic status of these countries; a correct estimate and comparison can be made between these countries when all the above issues are considered (13). For example, the policy of countries in diagnosing COVID-19 and performing RT-PCT testing is different. In
Italy, early in the epidemic, a second sample was tried to confirm the cases while in China a single test was done. The single-test strategy was also adopted in Iran. Due to a lack of diagnostic kits early in the epidemic, only in some cases was a test once taken from suspected people. On the other hand, $23 \%$ of the Italian population is over 60 years old, but this number is around $6 \%-7 \%$ in Iran. Also, the definition of death induced by COVID-19 is different in these countries and may lead to overestimation of deaths in some countries. Therefore, comparing countries in terms of
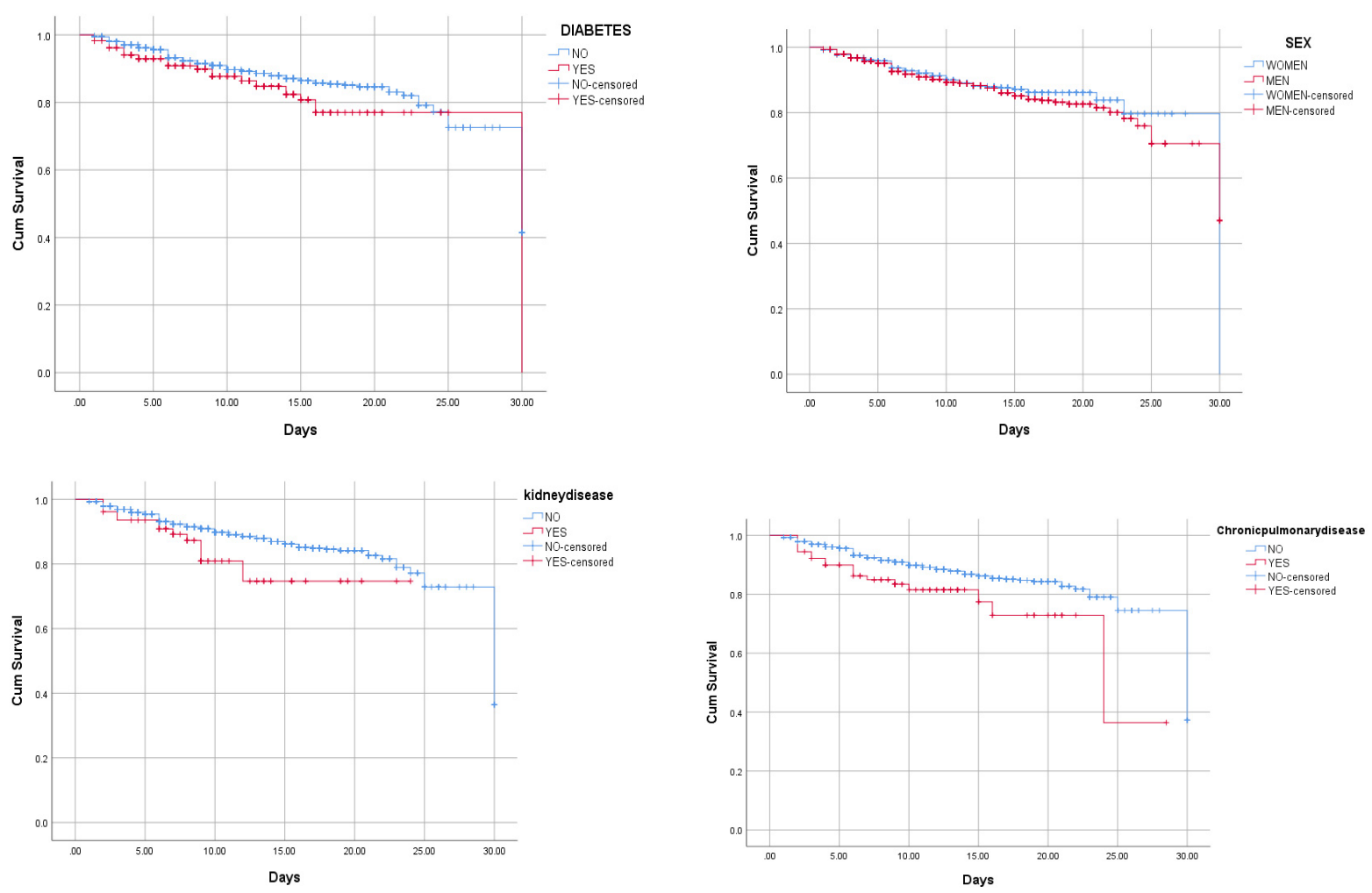

Fig. 2. Survival rate in patients with Coronavirus Disease 2019 (COVID 19) pneumonia based on gender (The log Rank Test: 0.92, Df: 1, p: 0.337), diabetes (The log Rank Test: 4.41, Df: 1, p: 0.036), kidney disease (The log Rank Test: 4.64, Df: 1, p: 0.031), and chronic pulmonary disease (The $\log$ Rank Test: 7.27, Df: 1, p: 0.007). 

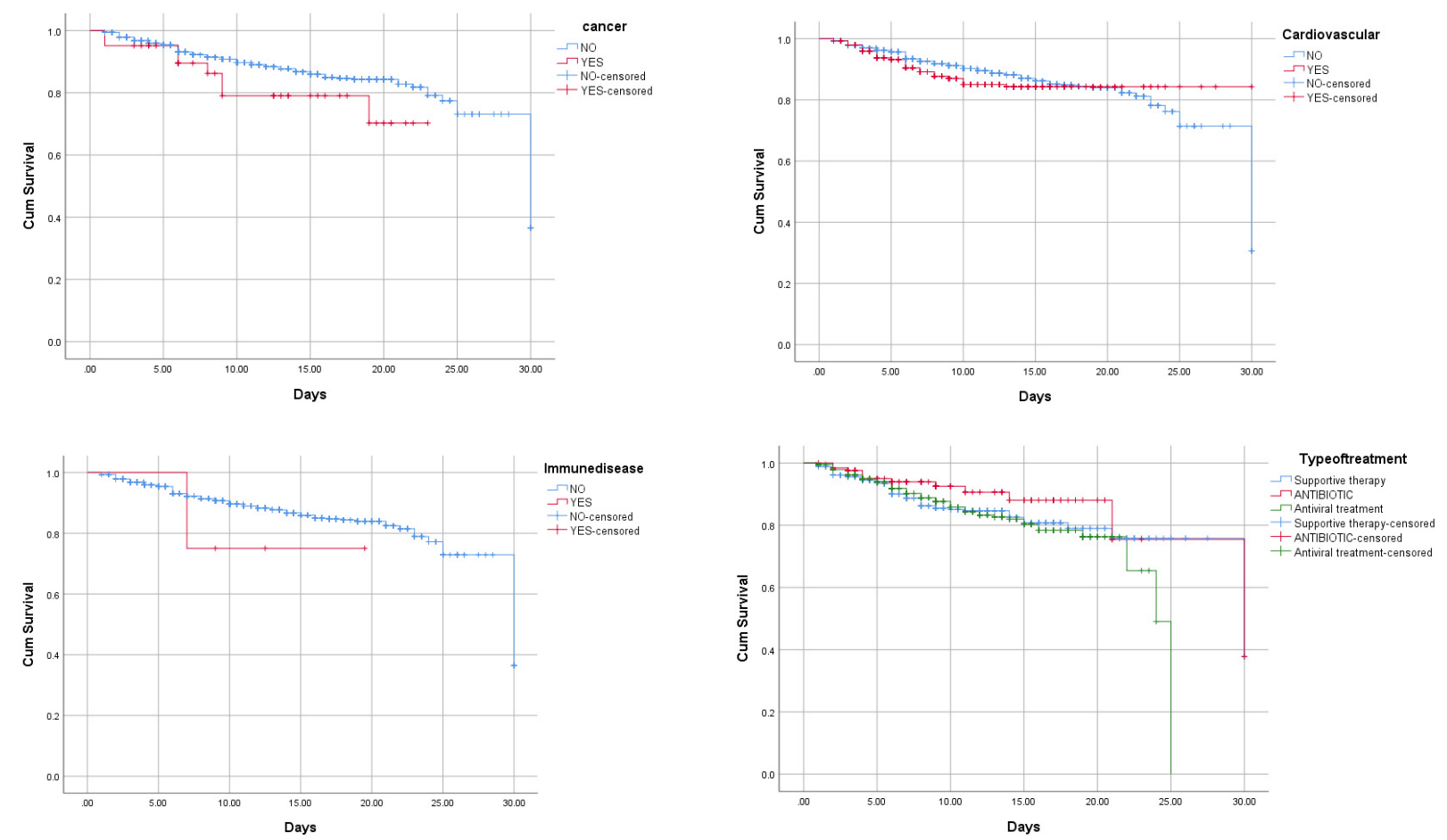

Fig. 3. Survival rate in patients with Coronavirus disease 2019 (COVID 19) pneumonia based on cancer (The log Rank Test: 2.49, Df: 1, p: 0.115), cardiovascular disease (The log Rank Test: 2.58, Df: 1, p: 0.108), immune disease (The log Rank Test: 0.58 , Df: $1, \mathrm{p}: 0.445$ ), and type of treatment (The log Rank Test: 2.92, Df: 1, p: 0.232).

death data based on age and sex variables will be a bit challenging. By obtaining accurate and factual information about COVID-19, in addition to the above and the ability to compare, it is possible to identify the natural course of the disease and its epidemiology to the extent that it will help to produce vaccines in the future (14-16).

The results of the present study showed the risk of death due to COVID-19 in men was higher than in women, which was in line with the results of studies by Chen C. et al and Carlos del Rio et al $(17,18)$. In China, COVID-19 death was $2.8 \%$ for men and $1.7 \%$ for women in mid-February. A similar situation existed before in the outbreak of SARS in Hong Kong in 2003; even the common flu affects men more severely than women. Men are generally at a higher risk than women in Iranian society because men generally work outside, so they are more likely to be at risk. Other reasons include poor immune system, poor lifestyle, and higher male interactions at the community level, while women's immune system is stronger because of greater care and health. One of the main reasons for boosting the immune system in women is female sex hormone, estrogen. In men, however, testosterone weakens the immune system (19). Another reason for the difference in COVID-19 mortality between men and women is genetic. Some immunerelated genes, such as genes that are responsible for identifying disease agents, are encoded on the $\mathrm{x}$ chromosome. Since women have $2 \mathrm{x}$ chromosomes and men have only 1 , women have more advantage (20-23).

Chronic diseases, such as diabetes, kidney disease, and chronic obstructive pulmonary disease, increased the risk of death in COVID-19 patients in this study. Among these diseases, chronic obstructive pulmonary disease (COPD) played a greater role. The US Center for Disease Control and Prevention reported that COVID-19 was a threat to public health and that older people with chronic medical conditions, such as diabetes, were at higher risk for severe illness and experiencing the side effects. Studies have shown if a person is diagnosed with diabetes, the risk of developing severe side effects of COVID-19 in these people is as high as in healthy people when the diabetes is controlled. If diabetes is not controlled and the person has fluctuating blood sugar, they are more likely to have problems with COVID-19. Heart disease and other diseases, along with diabetes, increase the severity of COVID-19 symptoms, as the case with other infectious diseases, because the body's ability to fight infection is reduced and the immune system is weakened. Finally, it can be concluded that all underlying diseases in a person with COVID-19 are important in that they weaken the immune system and expose the person to a more severe condition and even death. Now, if these underlying diseases have the same behavior as COVID-19, they will have a greater and more significant effect. For example, similar to COVID-19, chronic pulmonary obstruction affects the lungs and respiratory system, and if a person has both COVID-19 and chronic pulmonary obstruction, they will have a synergistic effect that is more serious and eventually leads to death (24-26). On the other hand, the results of a study by Leung and Janice M. et al showed active smoking and COPD increased the expression of ACE-2 gene in the lower airways, which may to some extent justify the increased risk of COVID-19 in these populations (24).

Regarding the effect of cardiovascular disease on increased mortality of COVID-19 patients, the results of the 
multivariable model of the present study showed that cardiovascular disease reduced the risk of death in these patients, but the relationship was not statistically significant. Most studies around the world have shown that cardiovascular disease can increase the risk of death in patients with COVID-19 (18, 27-30). According to studies, severe acute respiratory syndrome Coronavirus 2 (SARS-CoV-2) infects host cells through angiotensin ACE2 receptors, leading to COVID-19. It also causes acute myocardial damage and chronic damage to the cardiovascular system. Therefore, special attention should be paid to cardiovascular protection during COVID-19 treatment. In addition, people with cardiovascular disease or heart transplantation are more likely to develop severe side effects of COVID-19 and die from it due to a weakened immune system. COVID19 also increases the levels of troponin I and D, which is associated with increased incidence of cardiovascular disease or its exacerbation. According to a study by Anita Sabzghabaei et al, 72 hours after admission of COVID-19 patients, serum troponin levels were reported to be positive in about $70 \%$ of patients who were transferred to CCU due to symptoms of a cardiac origin. The initial troponin test of $50 \%$ of these patients was positive upon referral (31). The results of the multivariable model of the present study contradict those of studies conducted worldwide, which can be due to nonseparation of the analyzed data for hypertension, obesity, ischemic heart disease, and various other cardiovascular diseases. On the other hand, the method of diagnosing and identifying cardiovascular disease may have been less sensitive in the present study (18). Definition of COVID-19 death from cardiovascular disease may have also been altered or used with delay in different sections, in which case many COVID-19 deaths may not have been recorded due to previous illnesses or may have been recorded for other reasons. According to the results of the present study, the use of antibiotics increases the risk of death, while the use of antiviral drugs reduces the risk of death in patients with COVID-19. These results are in line with those of studies conducted around the world (32-36). In a study conducted in Italy as a clinical trial, the results showed the use of chloroquine with azithromycin can be useful in improving the symptoms of patients with COVID19. The results of this study showed that lung infection ends after 5 to 6 days in $100 \%$ of patients, and the patients begin to recover (37).

One of the limitations of this study was the way the data on cardiovascular disease was recorded. On the other hand, the number of deaths was not enough to calculate significant results for other causes of death in patients with COVID-19. Therefore, conducting studies with a larger sample size and more accurate recording of the causes of death for COVID-19 patients is highly recommended.

\section{Conclusion}

Based on the results of this study, more attention and care should be paid to COVID-19 patients with underlying diseases, such as chronic obstructive pulmonary disease, diabetes, and kidney disease to reduce the number of deaths. On the other hand, antiviral drugs can largely prevent death; however, more research is needed. These results could help health policymakers spend most of their budgets and facilities on COVID-19 patients with underlying diseases to reduce the number of deaths.

\section{Conflict of Interests}

The authors declare that they have no competing interests.

\section{References}

1. https://www.worldometers.info/coronavirus/\#countries [Internet]. 2020 Available from: https://www.worldometers.info/coronavirus/ \#countries.

2. Mizumoto K, Kagaya K, Chowell G. Early epidemiological assessment of the transmission potential and virulence of coronavirus disease 2019 (COVID-19) in Wuhan City: China, January-February, 2020. medRxiv. 2020 .

3. Organization WH. Coronavirus disease 2019 (COVID-19): situation report, 67. 2020.

4. Guan WJ, Ni ZY, Hu Y, Liang WH, Ou CQ, He JX, et al. Clinical characteristics of coronavirus disease 2019 in China. N Engl J Med. 2020.

5. Assiri A, Al-Tawfiq JA, Al-Rabeeah AA, Al-Rabiah FA, Al-Hajjar S, Al-Barrak A, et al. Epidemiological, demographic, and clinical characteristics of 47 cases of Middle East respiratory syndrome coronavirus disease from Saudi Arabia: a descriptive study. Lancet Infect Dis. 2013;13(9):752-61.

6. Wu F, Zhao S, Yu B, Chen Y-M, Wang W, Song Z-G, et al. A new coronavirus associated with human respiratory disease in China. Nature. 2020;579(7798):265-9.

7. Wu Z, McGoogan JM. Characteristics of and important lessons from the coronavirus disease 2019 (COVID-19) outbreak in China: summary of a report of 72314 cases from the Chinese Center for Disease Control and Prevention. JAMA. 2020

8. Chiu SS, Hung Chan K, Wing Chu K, Kwan SW, Guan Y, Man Poon LL, et al. Human coronavirus NL63 infection and other coronavirus infections in children hospitalized with acute respiratory disease in Hong Kong, China. Clin Infect Dis. 2005;40(12):1721-9.

9. Breban R, Riou J, Fontanet A. Interhuman transmissibility of Middle East respiratory syndrome coronavirus: estimation of pandemic risk. Lancet. 2013;382(9893):694-9.

10. DeDiego ML, Nieto-Torres JL, Regla-Nava JA, Jimenez-Guardeño JM, Fernandez-Delgado R, Fett C, et al. Inhibition of NF- $\mathrm{B}$-mediated inflammation in severe acute respiratory syndrome coronavirus-infected mice increases survival. J Virol. 2014;88(2):913-24.

11. Casanova L, Rutala WA, Weber DJ, Sobsey MD. Survival of surrogate coronaviruses in water. Water Res. 2009;43(7):1893-8.

12. Onder G, Rezza G, Brusaferro S. Case-fatality rate and characteristics of patients dying in relation to COVID-19 in Italy. JAMA. 2020.

13. Surveillances V. The epidemiological characteristics of an outbreak of 2019 novel coronavirus diseases (COVID-19) - China, 2020. CCDC Weekly. 2020;2(8):113-22.

14. Organization WH. Coronavirus disease 2019 (COVID-19): situation report, 72. 2020.

15. Organization WH. Coronavirus disease 2019 (COVID-19): situation report, 74. 2020.

16. Wu JT, Leung K, Bushman M, Kishore N, Niehus R, de Salazar PM, et al. Estimating clinical severity of COVID-19 from the transmission dynamics in Wuhan, China. Nat Med. 2020:1-5.

17. Del Rio C, Malani PN. COVID-19-new insights on a rapidly changing epidemic. JAMA. 2020.

18. Chen C, Yan J, Zhou N, Zhao J, Wang D. Analysis of myocardial injury in patients with COVID-19 and association between concomitant cardiovascular diseases and severity of COVID-19. Zhonghua Xin Xue Guan Bing Za Zhi. 2020;48:E008-E.

19. Liu W, Zhang Q, Chen J, Xiang R, Song H, Shu S, et al. Detection of Covid-19 in children in early January 2020 in Wuhan, China. New Engl J Med. 2020;382(14):1370-1.

20. Tolksdorf K, Buda S, Schuler E, Wieler LH, Haas W. Influenzaassociated pneumonia as reference to assess seriousness of coronavirus disease (COVID-19). Eurosurveillance. 2020;25(11):2000258.

21. Barrios JM, Hochberg Y. Risk perception through the lens of politics in the time of the covid-19 pandemic. NBER. 2020 Apr 16. 
22. Teymoori-Rad M, Samadizadeh S, Tabarraei A, Moradi A, Shahbaz MB, Tahamtan A. Ten challenging questions about SARS-CoV-2 and COVID-19. Expert Rev Respir Med. 2020 Sep 1.

23. Zhang H, Penninger JM, Li Y, Zhong N, Slutsky AS. Angiotensinconverting enzyme 2 (ACE2) as a SARS-CoV-2 receptor: molecular mechanisms and potential therapeutic target. Intensive Care Med. 2020 Apr;46(4):586-90.

24. Leung JM, Yang CX, Tam A, Shaipanich T, Hackett T-L, Singhera GK, et al. ACE-2 Expression in the Small Airway Epithelia of Smokers and COPD Patients: Implications for COVID-19. Eur Respir J. 2020.

25. Lippi G, Henry BM. Chronic obstructive pulmonary disease is associated with severe coronavirus disease 2019 (COVID-19). Respir Med. 2020

26. Emami A, Javanmardi F, Pirbonyeh N, Akbari A. Prevalence of underlying diseases in hospitalized patients with COVID-19: a systematic review and meta-analysis. Arch Acad Emerg Med. 2020;8(1).

27. Zhou F, Yu T, Du R, Fan G, Liu Y, Liu Z, et al. Clinical course and risk factors for mortality of adult inpatients with COVID-19 in Wuhan, China: a retrospective cohort study. Lancet. 2020.

28. Zheng YY, Ma YT, Zhang JY, Xie X. COVID-19 and the cardiovascular system. Nat Rev Cardiol. 2020;17(5):259-60.

29. Clerkin KJ, Fried JA, Raikhelkar J, Sayer G, Griffin JM, Masoumi A et al. Coronavirus disease 2019 (COVID-19) and cardiovascular disease. Circulation. 2020.

30. Driggin E, Madhavan MV, Bikdeli B, Chuich T, Laracy J, BondiZoccai G, et al. Cardiovascular considerations for patients, health care workers, and health systems during the coronavirus disease 2019 (COVID-19) pandemic. J Am Coll Cardiol. 2020.

31. Sabzghabaei A, Nazarian A, Nazarian Z, Malih N, Shojaee M. Evaluation of the Troponin Measurements Results in Patients with Acute Coronary Syndrome; a Brief Report. Iran J Emerg Med. 2016;4(1):35-9.

32. Stebbing J, Phelan A, Griffin I, Tucker C, Oechsle O, Smith D, et al. COVID-19: combining antiviral and anti-inflammatory treatments. Lancet Infect Dis. 2020;20(4):400-2.

33. Devaux CA, Rolain J-M, Colson P, Raoult D. New insights on the antiviral effects of chloroquine against coronavirus: what to expect for COVID-19? Int J Antimicrob Agents. 2020:105938.

34. Molina JM, Delaugerre C, Goff J, Mela-Lima B, Ponscarme D, Goldwirt L, et al. No evidence of rapid antiviral clearance or clinical benefit with the combination of hydroxychloroquine and azithromycin in patients with severe COVID-19 infection. Med Mal Infect. 2020:30085-8.

35. Mitjà $\mathrm{O}$, Clotet $\mathrm{B}$. Use of antiviral drugs to reduce COVID-19 transmission. Lancet Glob Health. 2020.

36. Colson P, Rolain JM, Lagier JC, Brouqui P, Raoult D. Chloroquine and hydroxychloroquine as available weapons to fight COVID-19. Int J Antimicrob Agents. 2020;105932(10.1016).

37. Gautret P, Lagier JC, Parola P, Meddeb L, Mailhe M, Doudier B, et al. Hydroxychloroquine and azithromycin as a treatment of COVID-19: results of an open-label non-randomized clinical trial. Int J Antimicrob Agents. 2020:105949. 